\title{
Analysis on the Ecological Basis of Resource Recycling
}

\author{
Tingting $\mathrm{Liu}^{1} \&$ Yufeng $\mathrm{Wu}^{1}$ \\ ${ }^{1}$ Insistute of Circular Economy, Beijing University of Technology, Beijing, China \\ Correspondence: Yufeng Wu, Insistute of Circular Economy, Beijing University of Technology, Chaoyang \\ Dirstrict, Beijing, 100122, China. Tel: 86-010-67396263. E-mail: circular_economy @ 163.com
}

\author{
Received: April 6, 2016 Accepted: May 18, 2016 Online Published: July 30, 2016 \\ doi:10.5539/jsd.v9n4p234 URL: http://dx.doi.org/10.5539/jsd.v9n4p 234
}

\begin{abstract}
Resource recycling is one of the most important content of ecological civilization construction in China, which is beneficial to reduce the overuse of primary resources exploitation, to reduce the environ mental pollutions during the process of resource extraction and waste disposal, and to realize the sustainable development of human economy and society. Resource recycling is a reflection of ecological economic development. Ecology provides a theoretical support for the resource circulation industry development. The ecological theories have played a guiding role. However, there are not enough academic researches to systematically summarize and analyze the relation and connection between ecology and resource recycling. Therefore, we based on the ecological theories to analyze the theoretical basis and application for resources recycling. The results showed that the ecological threshold theory, ecological balance theory, Overall hierarchy theory, the food chain (web) theory, niche theory and so on can be used to explain the resource circulation system such as resources recycling building concepts, resources recycling industry development foundation and the government's role in promoting resources circulation process. Based on the application of ecological theory for constructing the resource circulation system, further analysis of the scientific laws for the government regulation may help understand the concept of resource circulation and essence of circular economic system operation.
\end{abstract}

Keywords: ecological civilization construction, resource recycling, ecology, theory application

\section{Introduction}

The social development of human being relies on the development and utilization of resources substantially. Limitless development and utilization of primary resources gives rise to the resource crisis and draws the attention to sustainable development. It was proposed in the "the Eighteenth National Congress of the Communist Party of Ch ina" that the ecological civilization construction shall be placed in a prominent position, and resource recycling is a significant part of the ecological civilization construction. The circular using of resource is actually the manifestation of economic development ecologicalization. The primary research object of ecology shall be the ecosystem. The cyclic material utilization and energy flow type of the ecosystem is an efficient utilization of resource and energy. Human can absorb and refer to the circulation of materials and energy flow mode during the process of constructing resource circulation system, and adjust the economic development structure. Thus, it is able to realize the economic development mode of resource circulation. The ecological theory can be applied for guid ing the establishment of resource circulation system(Wang \& Yin, 2007; Liu \& Xie, 2010; Xu \& Li, 2005; Zhang, 2005). Therefore, it is necessary to conduct systematic analysis of the ecological theory for resource circulation. On that basis, illustrations are conducted from theories related to the resource circulation in ecology, and the analysis can be applied for guiding the construction of resource circulation system and development of resource circulation industry.

\section{Ecological Theories of Resource Recycling}

Ecology is the most important theoretical foundation followed by the development of circular economy. The ecological threshold value, ecological balance, overall hierarchy and food chain (net) theory in ecology can be applied for guiding the construction of resource circulation system. The ecological niche, biodiversity, mutualistic symbiosis, key species and Intermediate disturbance hypothesis can be applied for guiding the development of resource circulation industry.

\subsection{The Ecological Threshold Theory: Basis for the Launch of Resource Circulation}

The ecological threshold theory refers that the ecosystem holds certain endurance to the external interference. 
When the outside interference is over this limit, the ecosystem may lose stabilizing power and give rise to the system recession and extinction. As a result, the system structure and function may be injured and damaged. In the same way, the resource development also has certain threshold value. When the resource development exceeds the threshold value, it may lead to the resource crisis, and even the survival crisis. Resource circulation may reduce the exploitation of original resources. Therefore, the ecological threshold theory is the action basis for the launch of resource circulation.

\subsection{Ecological Balance Theory: Theoretical Basis for the Construction of Resource Circulation System}

Ecosystem is a complicated dynamic system, which carries out the material circulation and energy circulation at any moment. Each component of the system is in dynamic state. If each component of an ecosystem keeps relatively coordinated in a long time, the system would be in stable state. There is a relative balanced relation between the input and output of materials and energy, and among the producers, consumers and decomposers. At this moment, the structure and function of ecosystem may be in a dynamic balance with mutual adaptation and coordination. Such balance shall be the ecological balance. Besides the constant material output, the resource system also includes material input. It may guarantee the resource circulation and balance, and realize the sustainable development. Therefore, ecological balance theory is the theoretical basis for the construction of resource circulation system.

\subsection{Overall Hierarchy Theory: Theoretical Guidance for the Clarification of Resource Circulation Hierarchy and Synergic Relationship}

The natural ecosystems include several hierarch ies from microcosmic to macroscopic scale (species, population, community and ecosystem). When the system structure keeps being complicated, it may have new functions and features, namely the overall hierarchy theory (Fan, 2005). Resource circulation is also multi-layered, including minor-cycle of enterprise, medium circulation of the region and general circulation of the society. The coordination of different hierarchies of circulation is crucial for the realization of resource circulation. The overall hierarchy theory is favorable for guiding the clarification of coordinated development relation among hierarchies of the resource circulation.

\subsection{Ecological Food Chain Theory: Core Foundation for the Design of Resource Recycling System}

The biotic component of the ecosystem can be further divided into producers, consumers and decomposers. The materials and energy fixed in the photosynthesis by producers may be transmitted in the ecosystem through a series of predation relation. The organisms would be arranged according to the predation relation, which would form the food chain (Sun, Li, Niu, \& Lou, 2002). The food chains are intersected in the ecosystem, forming a net structure, namely the food web. All organisms in a certain link in the food chain would integrate into a trophic level. The materials and energy would flow from the previous trophic level to the next along the food chain. The trophic level of the food chain and food web plays different roles, namely, it forms the materials circulation and energy flow among the producers, consumers and decomposers (Zhang, 2005; Xie \& Wang, 2011). The food chain (web) theory can also be applied for guiding people to simulate the natural ecosystem and to plan the resource circulation and utilization process according to the ecological rules (Xie \& Wang, 2011).

\subsection{Ecological Niche Theory: Guidance for Improving the Resource Circulation Efficiency}

Ecological niche theory refers to the position of individuals, populations or community in multi-dimensional space of space, time, resource and environmental condition, as well as its functions in the ecosystem (Zhang, 2009). Each organism has specific ecological $n$ iche in nature, which is the resource and environ ment fo undation of its survival and development. There will be competitions between two completely overlapping species. The one with comparative advantages may eliminate the weaker species. Partially overlapping or completely different species may seek for certain coexisting state. The ecological niche theory main ly reveals the general performance of environmental resources among organisms, as well as the ultimate result of interactions (Zhang, 2009). When the eco-industry park of resource circulation is established, the ecological niche theory can be applied for determining the eco-industry park and ecological niche of the enterprise, so as to improve the resource circulation utilization and efficiency.

\subsection{Biodiversity Theory: Theoretical Reference for the Promotion of Resource Circulation Industrial Development}

Biodiversity theory refers to the diversity and variability of the life organisms and components of the life system. Ecosystem with high biodiversity usually has numerous advantages. For instance, it has strong anti-interference and anti-invasion ability, high resource utilization efficiency, and so on. Biodiversity is the foundation of ecosystem stability, and it will also optimize the functions of ecosystem (Ren, 2008). The biodiversity theory can 
be applied for guiding the design of industrial ecology and improving the circulation utilization of wastes and by-products.

\subsection{Symbiosis Theory: Scientific Guidance for the Establishment of Symbiotic Relationship of Resource Circulation Industry}

In ecology, symbiosis refers that different species in the same space may form the coexistence relation. The different species may be favorable for both parties or be favorable for one party and harmful for the other party. For instance, the symbiosis between the animals and microorganisms in the digestive tract, symbiosis between the leguminous plant and nitrogen-fixing bacteria, symbiosis between the epiphyte and the host, etc. In the construction of resource circulation system, it can refer to the symbiosis theory for establishing the symbiosis system and promoting the maximization of resource use efficiency.

\subsection{Key Species Theory: Theoretical Basis for the Selection of "Key Species Enterprise" in the Resource Circulation Industry}

"Key species" refers to the species with advantages in the community and certain impacts on other species. The key species play a vital role in maintaining the biodiversity of ecosystem. The weakening or disappearance of key species will impact the entire ecosystem substantially. The selection of "key species enterprises" can refer to the "key species" theory. It will be favorable for the construction of enterprise symbionts and promotion of resource circulation when designing the eco-industrial Park.

\subsection{Intermediate Disturbance Hypothesis: Theoretical Foundation for Guiding the Impact of Governmental Behaviors on the Development of Resource Circulation Industry}

Disturbance refers to the interference of external factors to the system, which is the motive force for the development of community, as well as the significant factor impacting the community structure and succession. In the unbalanced community, the highest biodiversity occurs when the disturbance is of moderate degree, namely the intermediate disturbance hypothesis proposed by Cornell in 1978. It can be applied for guiding the resource circulation process, in which the government may balance the matching of renewable resources and original resources, and promote the resource recovery and utilization process.

\section{Application of Ecological The ory in the Construction of Resource Circulation System}

\subsection{Application of Ecological Threshold Theory}

The resource carrying capacity and environmental cleaning capacity is limited. Once the resource consumption and pollution discharge degree exceeds the ecological threshold value, it may result in the environmental deterioration and shortages of resources. Meanwhile, it will impact the survival and development of next generations, and give rise to the survival crisis of hu mankind. Therefore, the resou rce exploitation quantity shall be controlled with in the resource carrying capacity during the production and construction of social economy, and the environmental pollution degree shall be controlled within the environmental adsorptive capacity. The construction of resource circulation system may be favorable for the reduction of resource consumption and environmental pollution, as well as the maintenance of social stability, balanced and sustainable development $(\mathrm{Li}$, 2006).

\subsection{Application of Ecological Balance Theory}

The concept of the construction of resource circulation system is originated from the understanding and comprehension of ecological balance theory. The balance of ecosystem is mainly reflected by the dynamic balance of the input and output of materials and energy among producers, consumers and decomposers. However, the traditional resource utilization mode consists of "resource exploitation - product production - consumption -waste discharge". It is a kind of unbalanced linear mode of single resource flow. It may result in the shortage and exhaust of resources. Meanwhile, wastes are discharged into the environment substantially in the processing and consumption process, which may result in the environ mental pollution. Such unbalanced development mode breaks the sustainable development of human society. Therefore, it shall construct a dynamic and balanced resource circulation system, by referring to the natural ecological balance theory, so as to establish material circulation process, covering the "resource explo itation - production - consumption - waste emission - resource regeneration". Consequently, there would be no or fewer wastes in the entire production and consumption process. All materials and energy can be recycled properly, and the resource consumption and environmental pollution produced in the economic activities may be minimized.

\subsection{Application of Overall Hierarchy Theory}

Human society is an artificial ecosystem dominated by human behaviors, with the resource flow as the lifeline, 
natural environ ment as reliance and social system as the collateral channels. It can be deemed as the complicated ecosystem of nature - economy and society (Wang Wang, Chi, \& Ouyang, 2001). The resource circulation and utilization is one of the core research contents about the sustainable development of nature-economy-society complicated ecosystem. How to create resource circulation process in such a complicated system? At first, it shall clarify the system hierarchy, from mic roscopic to macroscopic scale, and guide the construction of resource circulation system according to the overall hierarchy theory of ecosystem. The natural ecosystems consist of four hierarchies, namely the species, population, community and ecosystem. Correspondingly, resource circulation economic system can be constructed from three different levels. Firstly, establishing minor-cycle mode from the level of enterprise, which may correspond to the species and population in the natural ecosystem. It can realize the maximization of resource efficiency and minimization of pollution discharge in the production process through the development and utilization of cleaning production technology. Secondly, establishing moderate-cycle mode from the level of region, namely the community in natural ecosystem, in which the symbiosis enterprises or industries may form resource circulation network, and realize the regionalized scale circulation. Thirdly, establishing general circulation from the level of society, namely the ecosystem, the symbiosis network would be established among the sub-systems. The general resource circulation system constructed may realize the virtuous circle of materials and sufficient utilization of energy in the system. Meanwhile, it is also equipped with in formation feedback mechanism (Song, Han, Tong, \& Li, 2007).

\subsection{Application of Ecological Food Chain (Net) Theory}

The ecosystem realizes the material circulation, energy circulation and information transmission through food chain. The construction of resource circulation industry chain may refer to the food chain (net) theory, and put the resource exploiters, utilizers and regeneration cycle corresponding to each trophic level of the food chain in the ecological system (namely the producer, consumer and decomposer). For instance, Graedel and Allenby (2002) reflected the similarity between the resource circulation industrial chain and food chain of ecosystem through analyzing the circular flow process of copper in the resource recycling process (Graedel \& Allenby, 2002). In addition, according to the principle of food chain, in the resource circular agricultural development mode, the simulation of food chain construction in natural ecosystem may extend the orig inal length of industrial chain. It improves the resource and energy utilization efficiency. For instance, raising free-range chickens in economic forest - feeding pigs with chicken manure - making marsh gas with pig manure - fertilizer the field with biogas residue - raising fish in paddy field- the fish may eat the injurious insect for promoting the yield of rice. It forms a planting and breeding mode with network food chain, which has higher resource utilization efficiency and economic efficiency than the single mode (Wang, 2007).

Resource recycling food chain does not exist separately. Since the enterprise or industry in the food chain may be characterized by "polyphagy". Different "food chains" may form "food network". For instance, in the agricultural resource recycling field, Liuminying ecological village in Daxing District of Beijing takes the rice bran and crop straw produced in the grain processing as the fodder of farm, and then applies the excrements of livestock and partial straws for producing marsh gas as the living fuel. Meanwhile, the marsh gas residual will be processed into the folder or sent to the farmland or vegetable greenhouse as fertilizer, or sent to the fishpond for fish farming. The bottom mud of the fish-pond can be taken as the fertilizer of farmland and fruit land, so as to form the "food net" for the comprehensive utilization of material and energy (Zhang, 2010).

\section{Application of Ecological Theory in the Development of Resource Circulation Industry}

\subsection{Application of Ecological Niche Theory}

The ecological niche theory can be applied for guiding the design and location of units and organizations in the different resources recycling, which may be favorable for the development of resource cycle industry. For instance, ecological niche theory can be applied in the general social circulation for determining the ecological niche of resource cycling industrial park (eco-industrial park), and establishing featured resource recycling industrial park. The enterprise ecological niche shall be determined in the industrial recycling, so as to establish enterprise with comparative advantages and competitive advantages. The ecological niche of industrial park refers to the combination of natural factors and social factors that can be utilized. The determination of ecological niche of industrial park will be favorable for forming the comparative advantages, constructing resource circulation industrial chain and system stabilization, and avoid ing the vicious competition caused by the similar positioning. The ecological niche of enterprise refers to the summation of natural factors and social factors that can be utilized. Enterprise can establish the ecological niche and improve the competitiveness through differential management (Xie, 2011). In the same eco-industrial park and resource circulation network, if there are several enterprises of the same type shall be determined by the quantitative analysis of its ecological 
niche. The enterprises of resource cycling park can expand the ecological niche, improve the competitiveness and promote the development of resource circulation industry through scientific management, research and introduction of new technology and products, or improvement of service, etc.

\subsection{Application of Biodiversity Theory}

The diversity of resource recycling system can be reflected as the diversity of products, me mbers in the park or types of industrial park, or the diversity of input and output of the industrial system. The diversity may improve the system relevance of ecosystem and the cooperation of by-product cyclic utilization. For instance, the heat power station can apply the traditional fossil energy or agricultural wastes as the fuel. Meanwhile, the products of power station are also diversified. If the power station applies combined heat and power generation technology, it can also produce thermal energy and industrial stream, besides the electricity (Deng \& Wang, 2006).

\subsection{Application of Symbiosis Theory}

The symbiotic relationship established between industries (or enterprises) may play a vital role for the development of resource circu lation industry. Through cooperation, different industries (or enterprises) may take advantage of the wastes or by-products produced by each other for realizing the win-win of economy and environment. Such symbiotic relationship may be formed spontaneously or by planning. When industries (or enterprises) with coupling effect are allocated together, it may enhance the productivity, reduce the wastes and lower the material and energy consumption (Ju \& Sheng. 2008). Denmark Kalundborg eco-industrial Park mainly establishes a symbiotic cooperative relation among enterprises of the park. It includes the power plant, biological pharmacy, oil refinery, panel plant, sulphuric acid plant, cement plant, plantation and heating supply system in the Kalundborg residential area. Enterprises may take the wastes or by-products produced in the production process of other enterprises as raw materials or as alternative materials (Adamides \& Mouzakitis, 2009).

\subsection{Application of Key Species Theory}

"Key species" theory can be applied for designing the resource cycling industrial park, guiding the constructors to select the "key species enterprise" and constructing the enterprise symbiont with the industrial park as the core. "Key species enterprise" drive and contain the survival and development of other enterprises, and play a vital role for maintaining the stability of park and promoting the development of park. For instance, the Kalundborg eco-industry park mentioned in the symbiosis theory selects the power station as "key species enterprises". It takes advantage of the electricity, water and heating power, forms eco-industrial chain with other enterprises and forms the symbiotic relationship. As a result, the resources can be allocated properly, the wastes can be utilized effectively and the environmental pollution can be reduced to a relatively low level. Finally, it can realize the coordinated development of economy, environ ment and society (Domenech \& Davies, 2011).

\subsection{Application of Intermediate Disturbance Hypothesis}

Resource circulation process involves several subjects, which amount to the trophic level illustrated in the food chain (net) theory, namely producers (production enterprise), consumers (enterprise and residence) and decomposers (recyclable resource and recycling enterprise). The targets pursued by these subjects are distinct from the overall objects of social benefits. These distinctions result in the market failure and external problems in the resource circulation and utilization process, as well as the deficiency of power in the resource circulation and utilization. For instance, the manufacturing enterprises pursue for the maximization of enterprise economic benefit, rather than considering the environmental impacts and resource recovery degree produced by the production consumption. Consumers consider the maximization of efficiency, rather than the reduction of emission to a maximum extent for promoting the resource circulation. The recyclable resources enterprises are confronted by such problems as the insufficient waste recovery rate and low recyclable resource price. The government may further impact the behaviors of producers, consumers and recyclable resources users through establishing constraints and inventive mechanism. The government plays a significant role in the development of resource circulation industry, for it equals to the external disturbance in the entire system. Based on the Intermediate disturbance hypothesis in ecology, the moderate interference can promote the stability and development of system. Through making laws and regulations and establishing inventive mechanis ms, the government may correct the market failure, and develop new institutional space and good market environment for the resource circulation industrial development. Meanwhile, the government can take the responsibility as an intermediate disturber to breed and prefect the motive mechanism of the resource circulation economic development, enhance the comprehensive utilization of renewable resource and promote the development of recyclable resources industry. 


\section{Conclusion}

Resource circulation system is a composite system organizing the resource recycling activities by following the ecological theory and operation law of ecological systems with efficient resource metabolic process and integral system coupling structure. The ecological theory can be applied for explaining the concept of resource circulation system, development basis of resource circulation industry, as well as the function of government in the promoting of resource circulation process. Although China has already promoted the development of resource circulation industry actively, there are still problems of "recycling with diseconomy" in the resource utilization, and there is a lack of development power in the market economic environment. It is mainly caused by the failure of the formation of industrial scale and standardization, as well as imperfect legal system, policy supporting system and incentive mechanism. How to break the dilemma of "recycling with diseconomy"? It comes down to the dominance of government in leading and driving the development of resource circulation industry, constructing the system, mechanism and policy environment for the economic develop ment. Based on the application of ecological theory for constructing the resource circulation system, further analysis of the scientific laws for the government regulation may help understand the concept of resource circulation and essence of circular economic system operation, so that the resource circulation industry can play a positive role in the ecological civilization construction.

\section{Acknowledg ments}

This study was conducted as part of the "Biofuel production from waste cooking oil: Catering enterprises' participation willingness and incentive mechanism” (Item No.9164022) funded by Beijing Natural Science Foundation, and also supported by the Beijing municipal commission of education social science project (Item No.SM201610005011) and Beijing outstanding talent young scientists training program (Item No. 2015000020124G036).

\section{References}

Adamides, E. D., \& Mouzakitis, Y. (2009). Industrial ecosystems as technological niches. Journal of Cleaner Production, (17), 172-180. http://dx.doi.org/10.1016/j.jc lepro.2008.04.003

Deng, W. G., \& Wang, G. M. (2006). Introduction to Industrial Ecology. Beijing: China Social Sciences Publishing House.

Domenech, T., \& Davies, M. (2011). Structure and morphology of industrial symbiosis networks: The case of Kalundborg. Procedia - Social and Behavioral Sciences, $\quad$ (10), $79-89$. http://dx.doi.org/10.1016/j.sbspro.2011.01.011

Fan, Y. J. (2005). Introduction to Theoretical Basis of Cyclic Economy. Journal of Shandong University of Technology (Social Science Edition), (2), 10-16. doi:10.3969/j.issn.1672-0040.2005.02.002

Graedel, T. E., \& Allenby, B. R., translated by Shi, H. (2004). Industrial Ecology (Edition II). Beijing: Tsinghua University Press.

Ju, M. T., \& Sheng, L. X. (2008). Industrial Ecology. Beijing: Higher Education Press.

Li, Y. Y. (2006). Research on the Operating Mechanism of Cyclic Economy. Doctoral Dissertation, Nankai University.

Liu, X. H., \& Xie, Y. (2010). Analysis on Circular Economy in View of Ecology. Productivity Research, (11), 18-20.

Ren, H. Z. (2008). Introduction to Restoration Ecology (Edition II). Beijing: Science Press.

Song, T., Han, L., Tong, L. J., \& Li, M. S. (2007). Analysis on the Cleaner Production, Industrial Ecology and Cyclic Econo my in Ecology Pattern. Journal of Zoology and Rural Environment, (3), 86-89.

Sun, R. Y., Li, Q. F., Niu, C. J., \& Lou, A. R. (2002). Basic Ecology. Beijing: Higher Education Press.

Wang, J. (2007). Theory and Research Method of Cyclic Economy. Beijing: Business Daily Press.

Wang, R. S., Chi, J., \& Ouyang, Z. Y. (2001). Ecological Integration Method for the Sustainable Development of Medium and Small Town. Beijing: Meteorological Press.

Wang, Z. H., \& Yin, J. H. (2007). Industry Ecological and Circular Economy Theory: A Research Review. Scientific Management Research, (1), 25-28.

Xu, F., \& Li, J. H. (2005). Study of Principle and Model of Enterprise Niche. China Soft Science, (5), $130-139$.

Zhang, J. E. (2005). Tourism Ecology. Beijing: Che mical Industry Press. 
Zhang, J. E. (2010). Agricultural Circular Economy. Beijing: Chemical Industry Press.

Zhang, L. Q. (2005). The Ecological Principles of Cyclic Econo my. Journal of Hebei University of Economics and Trade, (3), 28-33.

Zhang. J. E.(2009). Ecological Planning. Beijing: Chemical Industry Press.

Zheng, Z., \& Wang, Q.F. (2009). Annotation of Ecology in Cyclic Economy. Business Times, (28), 15-16.

\section{Copyrights}

Copyright for this article is retained by the author(s), with first publication rights granted to the journal.

This is an open-access article distributed under the terms and conditions of the Creative Commons Attribution license (http://creativecommons.org/licenses/by/4.0/). 